\title{
LOS CRONICA COMVNIA: UNA CRÓNICA LATINA DE ORIGEN BARCELONÉS DEL SIGLO XIII. EDICIÓN Y ESTUDIO*
}

\author{
THE CRONICA COMVNIA: A BARCELONIAN LATIN CHRONICLE \\ FROM XIII ${ }^{\text {th }}$ CENTURY. EDITION AND STUDY
}

\author{
Jose Carlos Martín-Iglesias \\ Universidad de Salamanca (USAL)
}

Resumen: Este artículo ofrece la editio princeps de los Cronica comunia, una compilación de noticias de carácter analístico redactada en Barcelona en el último tercio del siglo XIII. Junto con la edición del texto y el estudio de su transmisión manuscrita y sus fuentes, el artículo presenta la posición de esta obra dentro de la tradición de los denominados annales Barcinonenses, la traduce y analiza la veracidad de las noticias históricas que contiene.

Palabras clave: Anales, Historiografía, Corona de Aragón, Cataluña, Edad Media.
Summary: This article provides the editio princeps of Cronica comunia, a compilation of annalistic news written in Barcelona in the last third of the XIII $^{\text {th }}$ Century. In addition to editing the text and the study of its manuscript transmission and its sources, the paper presents the position of Cronica сотиnia in the tradition of so-called annales Barcinonenses, translates the work and analyzes the accuracy of the historical information it conveys.

Keywords: Annals, Historiography, Crown of Aragon, Catalonia, Middle Ages.

\footnotetext{
* Este artículo se inscribe en las líneas de investigación de los proyectos SA261A11-1 y FFI2012-35134. Abreviaturas utilizadas: $D B E=$ Diccionario biográfico español, 50 vols., Madrid, Real Academia de la Historia, 2010-2013; DHEC = Diccionari d'història eclesiàstica de Catalunya, eds. Ramon CoRTs Blay.-Joan Galtès Pujol.-Albert Manent Segimon, 3 vols., Barcelona, Claret, 1998-2001; DHGE = Dictionnaire d'Histoire et de Géographie Ecclésiastiques, Paris, Letouzey et Ané, 1912-2011 (en curso de publicación); Díaz = Manuel Cecilio Díaz y Díaz, Index Scriptorum Latinorum Medii Aevi Hispanorum, 2 vols., Salamanca, Universidad de Salamanca, 1958-1959 (Acta Salmanticensia, Filosofía y Letras, 13,1-2); RFHMA = Repertorium fontium historiae Medii Aevi, 11 vols, Roma, Istituto Storico Italiano per il Medio Evo, 1962-2007.
} 


\section{INTRODUCCIÓN: LA FAMILIA DE LOS ANNALES BARCINONENSES}

Los Cronica comunia (Díaz 1356) son una breve compilación analística que abarca la historia del mundo desde Adán hasta el año 1270 d. C., fecha en la que concluyen con la muerte de Luis IX de Francia en Túnez ${ }^{1}$. Han permanecido inéditos hasta la fecha.

Por su origen y por el tipo de noticias que recogen, los Cronica comunia pertenecen a la tradición historiográfica de los cronicones Barcinonenses, según expresión de Coll Alentorn ${ }^{2}$. Es decir, unos textos organizados en forma de anales con abundantes noticias sobre la ciudad de Barcelona, de origen barcelonés y carácter civil frente al carácter fundalmente monástico, o al menos eclesiástico, de otras tradiciones historiográficas de la Cataluña medieval. Es frecuente asimismo que estos cronicones, o anales, por utilizar una denominación más de nuestro tiempo, se transmitan en manuscritos de contenido eminentemente jurídico.

De acuerdo con el estudio de Coll Alentorn, el origen de esta tradición parece remontar a mediados del siglo XII, en que se compiló el denominado Cronicón de Sant Cugat (ca. 1153-1162), el testimonio más antiguo conocido de la época de gestación de esta familia de anales ${ }^{3}$. Los siguientes testimonios

1.- Advierto ya que el título, presente en los dos manuscritos que transmiten esta obra, es un nominativo plural neutro, no un femenino singular (en este caso el autor habría escrito: «Cronica comunis»). Apenas hay bibliografía sobre ella. El estudio fundamental sigue siendo el de Miquel Coll Alentorn, "La historiografia de Catalunya en el període primitiu", Estudis Romànics, 3 (1951-1952), pp. 139-196 (reimpr. en IDEM, Historiografia, Barcelona, Curial, 1991 [Textos i estudis de cultura catalana, 21; Obres de Miquel Coll i Alentorn, 1], pp. 11-62), en las pp. 164 165. También le dedica un pequeño párrafo Tomás de Montagut Estragués, "Estudio jurídico", en Jaume Sobrequés Callicó.-Sebastià Riera Viader.-Manuel Rovira Solà.-Tomás de Montagut Estragués.-Joaquín Yarza Luaces, Llibre Verd de Barcelona, vol. 1, Barcelona, Base, 2004 (Apographa historica Cathaloniae. Sèrie històrica, 8), pp. 215-255 (=ibid., "Estudi jurídic", pp. 59-98), en las pp. 224-225.

2.- Vid. M. Coll, "La historiografía” cit., pp. 162-171. Pueden consultarse además: Sebastià RierA Viader.-Josep David Garrido Valls, "Cronicons Barcinonenses", Diccionari d'historiografia catalana, dir. Antoni Simon TARrés, Barcelona, Enciclopèdia Catalana, 2003, pp. 390-392; Francisco BAutista, "Breve historiografía: Listas regias y Anales en la Península Ibérica (siglos VII-XII)", Talia dixit, 4 (2009), pp. 113-190 (http://www.eweb.unex.es/eweb/arengas/td4Bautista.pdf) (02/09/2013), en las pp. 167-170, que se sirve la expresión más moderna de "anales barceloneses" y se aparta en algunos puntos de las conclusiones de su antecesor; y David Garrido VAlls, "Chronicones Barcinonenses", en The Encyclopedia of the Medieval Chronicle, ed. Graeme Dunphy, 2 vols., Leiden-Boston, Brill, 2010, vol. 1, pp. 303-304 (el título de la entrada es muy desafortunado, pues se esperaría «Annales Barcinonenses» o «Chronica Barcinonensia»). Aquí seguiré las tesis de Coll Alentorn, que matizaré en algún punto en concreto.

3.- Edición de Miquel Coll Alentorn, "El Cronicó de Sant Cugat", Analecta Montserratensia, 9 (1962) (=Miscel-lània Anselm M. Albareda, vol. 1), pp. 245-259 (reimpr. en IDEM, Historiografia, cit., pp. 65-82). D. GARrIDo, "Chronicones", cit., p. 303, se refiere a él como Chronicon Cucufatense. 
conservados son el denominado Cronicón de Skokloster (Díaz 1035) ${ }^{4}$ (ca. $1180)^{5}$ y el Chronicón Mallorquín (citado también como Chronicon Maioricense, Annales Maioricenses y Chronicon regis Roberti) (Díaz 1236) (ca. 1239) ${ }^{6}$. Todos ellos fueron redactados en latín.

Llegamos así a los Cronica comunia, cuya datación tradicional se sitúa hacia el año 1270, pero quizás deba retrasarse algunos años y situarse hacia 1276, como veremos. Los annales Barcinonenses compilados a partir de esta fecha alternan el latín con el catalán. En esta última lengua están redactados el Cronicó Barceloní I (ca. 1295-1301) y el Cronicó Barceloní II (ca. 1298) ${ }^{7}$.

En el siglo XIV esta tradición analística habría continuado en latín, de acuerdo con Coll Alentorn, con los denominados Chronicon Barcinonense I (Díaz 1999) (hasta 1311) y Chronicon Barcinonense II (hasta 1311), ambos del reinado de Jaime II de Aragón (1291-1327), probablemente de hacia $1323^{8}$. En

4.- Díaz y Díaz lo recoge con el título de Annales Barcinonenses. También aparece recogido con el mismo título en RFHMA, vol. 2, p. 251 (“Annales Barcinonenses, a. 751-1149"); y D. GARRIDO, "Chronicones", cit., p. 303, se refiere a él como Chronicon Monasterii Sko.

5.- Edición de Miquel Coll Alentorn, "El Cronicó de Skokloster", en Miscel-lània històrica catalana. Homenatge al P. Jaume Finestres, historiador de Poblet $(† 1769)$, Poblet, Abadía, 1970 (Scriptorium Populiti, 3), pp. 137-146 (reimpr. en IDEM, Historiografia, cit., pp. 83-92).

6.- Edición de Juan Pérez Villamil, "Chronicón Mallorquín”, Memorial Histórico Español, vol. 2, Madrid, 1851, pp. 425-435 (publicado sin nombre de autor, pero vid. Florencio Friera SuÁrez, "Juan Pérez Villamil: historiador, académico y director de la Real Academia de la Historia", Boletín de la Real Academia de la Historia, 203/1 [2006], pp. 17-61, esp. p. 60), e IDEM, Historia civil de la isla de Mallorca. Estudio preliminar, edición y notas Jesús Mella Pérez, Julio Antonio Vaquero Iglesias, Palma de Mallorca, Ajuntament, 1993, pp. 198-206. Aparece recogido en RFHMA, vol. 3, p. 378 ("Chronicon Maioricense").

7.- El Cronicó Barceloní I ha sido editado por Sebastià Riera Viader, "El Cronicó Barceloní I", Acta Historica et Archaeologica Mediaevalia, 22 (2001), pp. 257-262. El Cronicó Barceloní II se conserva en el códice El Escorial, Real Monasterio de San Lorenzo, o.I.12, del siglo XIV, ff. 96v-98v, vid. Julián Zarco Cuevas, Catálogo de los manuscritos Catalanes, Valencianos, Gallegos y Portugueses de la Biblioteca del Escorial, Madrid, Tip. de Archivos, 1932, pp. 68-69). Este segundo cronicón continúa inédito, salvo error por mi parte.

8.- El denominado Chronicon Barcinonense I fue publicado por Luc D'ACHERY, Veterum aliquot scriptorum qui in Galliae bibliothecis, maxime Benedictinorum latuerant, Spicilegium, vol. 10, Parisiis, 1671, pp. 621-625 (reproducido en José SÁENZ DE AGUIRre, Collectio maxima conciliorum omnium Hispaniae et novi orbis, vol. 3, Romae, 1694, pp. 544-546; y Luc D’ACHERY.-Étienne BALUZE.-Edmont MARTÈne, Spicilegium sive Collectio veterum aliquot scriptorum qui in Galliae bibliothecis delituerant, vol. 3, Parisiis, 1723 [reimprimida en Farnborough, Gregg International, 1968], pp. 140-142; de donde pasó a Enrique Flórez.-Manuel Risco, España Sagrada, vol. 28, Madrid, 1764, pp. 323-328). Hay que advertir, no obstante, que d'Achery se limitó a reproducir la transcripción del texto que le proporcionó Charles du Fresne, señor de du Cange, de modo que, en realidad, la autoría de la edición debe atribuirse a Du Cange, vid. ACHERy, Veterum aliquot scriptorum, cit., pp. 23-24. El denominado Chronicon Barcinonense II, por su parte, fue publicado por É. BALUZE en Pierre de MARCA, Marca Hispanica sive Limes Hispanicus, hoc est, geographica \& historica descriptio Cataloniae, Ruscinonis, \& circumjacentium populorum, Parisiis, 1688, cols. 753-758 (=E. Flórez.-M. Risco, España Sagrada, vol. 28, cit., pp. 328-334). Estos dos cronicones aparecen recogidos en RFHMA, vol. 3, p. 279 ("Chronicon Barcinonense I" y "Chronicon Barcinonense II"). 
realidad, se trata de una misma obra, que denominaré Annales Barcinonenses anni 1311, transmitida por el manuscrito Paris, BnF, lat. 4671A, de finales del siglo XV y origen catalán, ff. viIra-IXvb ${ }^{9}$.

Por esas mismas fechas se habría compuesto, todavía según la opinión de Coll Alentorn, el Chronicon Barcinonense III (ca. 1323-1327), inédito hasta el momento y conservado en el códice Madrid, Biblioteca Nacional, 18060, de finales del siglo XIV, ff. 138r-142 $\mathrm{r}^{10}$. Este manuscrito conserva en los ff. 138r-143r un corpus historiográfico formado por diferentes piezas, estrechamente relacionadas algunas de ellas, en efecto, con la familia de los annales Barcinonenses. Éstas son las siguientes: ff. 138r-142r, el Chronicon Barcinonense III de Coll Alentorn, en el que se distinguen tres partes, a saber, 23 entradas que abarcan desde la conquista de Barcelona por Almanzor en 985 hasta la de Valencia por Jaime I de Aragón en 1238 (ff. 138r-139r), 15 entradas que abarcan desde la expulsión de los sarracenos de Barcelona en el año 801 por Luis el Piadoso (814-840) hasta la muerte de Luis IX de Francia en 1270 (f. 139r-v), y 47 entradas más que comienzan con un cómputo de los años del mundo desde la creación hasta el nacimiento de Cristo y concluyen con el inicio de la expedición contra Cerdeña y Córcega en 1323, en tiempos de Jaime II de Aragón (1291-1327) (ff. 139v-142r), en virtud de esta última datación estos anales deberían denominarse simplemente Annales Barcinonenses a. 1323 ; f. $142 \mathrm{v}$, unos pequeños anales que comienzan con el nacimiento de Cristo y dedican la última entrada a una victoria del rey Ramiro I de Asturias (842/3-850) contra el invasor gracias a la asistencia del apóstol Santiago, noticia que aparece fechada en la era $872(\text { a. } 834)^{11}$, la datación de todas

9.- Así se advierte ya en el Recueil des historiens des Gaules et de la France, vol. 12, Paris, 1877, p. 380, nota a). Trataré de demostrarlo en otro trabajo dedicado específicamente al corpus historiográfico transmitido por Paris, BnF, lat. 4671A. Sobre este manuscrito, vid. François AvRIL.-Jean.-Pierre ANIEL.Mireille Mentré.-Alix Saulnier.-Yolanta Zatuska, Manuscrits enluminés de la Péninsule Ibérique, Paris, Bibliothèque Nationale de France, 1982, n⿳ 238 (p. 174). Puede descargarse de forma gratuita de la página electrónica de la Bibliothèque numérique Gallica de la Bibliothèque Nationale de France, basta con introducir como término de búsqueda: Latin 4671A.

10.- Vid. José Gómez Pérez, "Manuscritos del Toledano”, Revista de Archivos, Bibliotecas y Museos, 67 (1959), pp. 127-164, en las pp. 146-150. Advierto que puede descargarse de la entrada correspondiente a este códice en el catálogo en la red de la Biblioteca Nacional de España una excelente reproducción en color. Basta con introducir como término de búsqueda: Mss/18060.

11.- Es una clara referencia a la batalla de Clavijo, que se ha querido fechar en el a. 844, vid., por ejemplo, Joseph F. O'Callaghan, Reconquest and Crusade in Medieval Spain, Philadelphia, University of Pennsylvania Press, 2003 (The Middle Ages series), pp. 194-195. El mismo episodio es relatado con mayores pormenores por Lucas de Tuy, Chronicon mundi, lib. 4,17 (ed. Emma Falque, Lucae Tudensis Chronicon Mundi, Turnhout, Brepols, 2003 [CC CM 74], pp. 238-239); y Rodrigo Jiménez de Rada, Historia de rebus Hispanie, lib. 4,13 (ed. Juan Fernández Valverde, Roderici Ximenii de Rada Opera omnia, Pars I. Roderici Ximenii de Rada Historia de rebus Hispanie siue Historia Gothica, Turnhout, Brepols, 1987 [CC CM 72], pp. 132-133). Estos anales coinciden en su inicio con la cronología que se lee al final de la primera redacción de las Vitas sanctorum de Rodrigo de 
estas noticias por la era hispánica explica que las dos últimas entradas de esta parte estén dedicadas a comentar el modo de reducir la era hispánica al año de la encarnación, para lo que se utiliza un ejemplo referido al año 1300 (f. $142 \mathrm{v}$ ); ff. 142v-143r, una breve noticia titulada De compoto Lodonyci notabile, consagrada a explicar la equivalencia entre los años de la encarnación y la datación por los reinados de Luis VI de Francia (1108-1137) y Luis VII de Francia (1137-1180); y f. 143r, un pequeño párrafo sobre los soldados más valerosos entre los griegos y romanos, los judíos y los cristianos, entre los que se incluye a Godofredo de Bouillon $(\dagger 1110)$ como personaje más moderno.

Todavía dentro del siglo XIV pueden citarse otros dos anales de la familia barcelonesa compilados en centros monásticos de Gerona, unos en Santa María de Ripoll y los otros en Sant Feliu de Guíxols. Los primeros (Díaz 2125), redactados en latín y sólo parcialmente publicados, fueron reunidos hacia 1334 y se conservaban en un manuscrito de Ripoll de finales del siglo XIV que parece perdido ${ }^{12}$. Coll Alentorn no les da título alguno, pero en virtud de su datación podrían denominarse simplemente Annales Barcinonenses $a$. 1334. Los segundos son aún menos conocidos, puesto que siguen inéditos. Coll Alentron señala que se conservan en el códice Gerona, Biblioteca Pública, 97 y que su última de entrada lleva fecha de $1392^{13}$. He podido consultar el manuscrito gerundés y puedo proporcionar alguna información suplementaria. El códice, ejecutado en el último tercio del siglo XV, trans-

Cerrato en los códices London, British Library, Add. 30057, f. 175rb-vb, y Madrid, Biblioteca de la Universidad Complutense, 146, siglo XIV, ff. CCLIXva-CCLXra, pero no se encuentra en el otro ejemplar de esta compilación hagiográfica, Segovia, Archivo de la Catedral, B-275, que transmite la segunda redacción de esta obra (vid. Francisco Villamil Fernández, Rodrigo de Cerrato. Vitas sanctorum. Estudio y edición, Santiago de Compostela, Universidade de Santiago de Compostela, 1992 [Teses en microficha núm. 240], pp. 620-623). Esta cronología ha sido editada por Enrique Flórez, España Sagrada, vol. 2, Madrid, 1747, pp. 205-206, y ha recibido el nombre de Chronicon Cerratense (Díaz 1442). En ella, la citada batalla aparece fechada tanto en la era 972 (códice londinense), como en la era 963 (códice madrileño).

12.- Fue editado parcialmente por Jaime VillanueVA, Viage literario a las iglesias de España, vol. 8, Valencia, 1821, pp. 227-233. Díaz y Díaz lo recoge en su Index con el título de Chronicon varium in cod. Barcelona ACA Ripoll 22 siglos XII-XIV, pero la signatura que proporciona es la antigua que ofrece Villanueva. Este manuscrito aparece en el inventario de Bofarull de comienzos del siglo XIX, vid. Fernando Valls Taberner, Códices manuscritos de Ripoll. El inventario de 1823 de Próspero de Bofarull, Málaga, Universidad de Málaga, 1991 (=IDEM, "Códices manuscritos de Ripoll”, Revista de Archivos, Bibliotecas y Museos, 35 [1931], pp. 5-15 y 140-175), p. 22 (=p. 145), quien no lo identifica con ningún manuscrito actual, como tampoco lo hacen Ignasi M. Puig Ferreté.-M. Assumpta Giner Molina, Índex codicològic del Viage literario de Jaume Villanueva, Barcelona, Institut d'Estudis Catalans, 1998 (Memòries de la Secció Histórico-Arqueològica, 49), no 506 (p. 101 y p. 164) (en colaboración con Jesús Alturo Perucho en el apartado dedicado a la identificación de los códices manejados por Villanueva).

13.- Sobre los anales de Sant Feliu de Guíxols, vid. M. Coll, "La historiografía" cit., p. 169 (y n. 84 de esa página); D. GARRIDO, "Chronicones", cit., p. 303, que se refiere a ellos como Chronicon Felicense y los fecha en el siglo XV por un error fácilmente explicable y del que me ocuparé más adelante. 
mite los anales de Sant Feliu de Guíxols en los ff. ff. 82va-83ra ${ }^{14}$. Este texto está escrito en catalán y lleva por título «Kalendaris de molts fets antichs que.ls bons reys de Aragó han fets en pendre ciutats he viles de poder de moros he d'altres fets, segons que·s seguéxan». Comienzan con la conquista de Barcelona por Almanzor en el año 985, si bien el suceso aparece fechado erróneamente en 980: «En l'any de la incarnatió .DCCCLXXX. fou prese Barchinona». La última entrada lleva fecha de 1312, pero, tal y como señaló Coll Alentorn, es un error por el año 1392: «L'any de la natiuitat .MCCCXII. passà l'infant don Martí, duc de Mont Blanc, ab gran stoll en Cicília». Llama la atención, por otro lado, que la antepenúltima entrada se presente fechada en 1475: «L'any .MCCCCLXXV. intre l'infant de Malorques ab .II ${ }^{\mathrm{m}}$. lances e fou gran mortaldat he fam en aquel any». Pero se trata claramente de un error de copia por 1374 ó 1375 , pues la noticia versa sobre la invasión de Cataluña por parte de Jaime IV de Mallorca, iniciada en 1374 y que concluyó al año siguiente con la muerte del infante ${ }^{15}$. En la historia de Cataluña el año 1374 es famoso asimismo por haber sido «l'any de la fam» ${ }^{16}$. En definitiva, esta nueva pieza podría recibir la denominación de Annals de Barcelona de 1392.

El siguiente testimonio se sitúa ya a comienzos del siglo XV (ca. 1405), se trata del Cronicón de Guillermo Mascaró, el único de un autor conocido de esta tradición historiográfica ${ }^{17}$. Coll Alentorn se refiere a él con la denominación de Chronicon Barcinonense $I V$. Está inédito y se conserva en dos manuscritos: Barcelona, Biblioteca de Cataluña, 485, del siglo XV, ff. 241r-259r y ff. 271v-272v (continuación del f. 246v), y su apógrafo Madrid, Biblioteca de la Real Academia de la Historia, 9-4560 (olim 9-19-4-63), cuadernillo $\mathrm{n}^{\mathrm{o}} \mathrm{I}^{18}$, ff. $2 \mathrm{r}-13 \mathrm{r}$ y $14 \mathrm{r}-31 \mathrm{r}$, una copia ejecutada en el siglo XIX

14.- Sobre este ejemplar puede consultarse Eulàlia DuRAN (dir.), Repertori de manuscrits catalans (14741620), vol. 4, Barcelona, 2008, (Institut d'Estudis Catalans. Memòries de la Secció Històrico-Arqueològica, 81), pp. 120-122 (noticia de Glòria Sabaté Marín), donde se recoge un excelente estudio del volumen y una completa descripción de sus contenidos, incluidos los anales que aquí interesan (con su título, incipit y desinit).

15.- Vid. J. Ernest Martínez Ferrando, La tràgica històrica dels reis de Mallorca, Barcelona, 1960 (Biblioteca Biogràfica Catalana, 21), pp. 268-272; Rafael TAsis MARCA, La vida del rei en Pere III, Barcelona, $1961^{2}$ (Biblioteca Biogràfica Catalana, 5), pp. 278-279.

16.- Vid., por ejemplo, Carles Puigferrat Oliva, "Fam, guerra i pesta a la Plana de Vic, 1374-1376", Ausa 19 (2000), n 144 , pp. 73-106.

17.- Ha sido objeto de estudio asimismo por Joan Ferran CABEstany Fort, "El Cronicó de Guillem Mascaró: l'autor i l'obra", en Miscel-lània Aramon i Serra: estudis de llengua i literatura catalanes oferts a R. Aramon i Serra en el seu setantè aniversari, vol. 2, Barcelona, Curial, 1980 (Estudis universitaris catalans, 24), pp. 115-122, quien expone la biografía del autor, describe el códice y edita un pequeño pasaje de los ff. 285r-v y 310v dedicado a la visita del rey Martín I de Aragón (1396-1410) al papa Benedicto XIII en Avignon en 1397.

18.- Lleva por título: «Chronica duo Barchinonensia. Ex codice Bibliot. Domini de Dalmaces eiusdem urbis, saec. XV ineunte in papyro ms.». Consultado en su lugar de depósito. 
por Jaime Villanueva ${ }^{19}$. Si bien Mascaró murió en 1405, su cronicón recoge dos entradas sobre los años 1405 y 1406 añadidas por un poseedor posterior del manuscrito y una entrada final correspondiente al año 1452 que parece ajena en buena medida al resto de la obra. Ésta, aunque redactada en latín, incluye alguna sección en catalán, sobre todo hacia el final.

Sólo unos pocos años después parece haber sido compilado el denominado Chronicon Vlianense (ca. 1409), todo él en latín ${ }^{20}$. Su título se debe a que se conservaba en un manuscrito del monasterio de Santa María de Ullá (Gerona), hoy desaparecido ${ }^{21}$.

Hay que añadir a esta lista unos últimos anales, poco conocidos, denominados por su editor Cronicón de los Dominicos de Mallorca, por conservarse en un manuscrito del siglo XVII que perteneció al convento de Santo Domingo de la Orden de Predicadores en Mallorca: Palma de Mallorca, Archivo del Reino de Mallorca, C-4739, ff. 38r-41 v $\mathrm{v}^{22}$. La más antigua se refiere a la conquista de Barcelona por los sarracenos en el a. 985 (fechada en el a. 900 en la obra) (f. 38r) y la más reciente corresponde al año 1552 (f. 41v). Las noticias presentan un cierto desorden cronológico. Las que versan sobre los siglos X-XIV están redactadas en latín (ff. 38r-40r), mientras que las de los siglos XV-XVI aparecen en catalán, con abundantes diferencias ortográficas con respecto a la única edición disponible (ff. $39 \mathrm{v}-41 \mathrm{v}$ ). Las siete primeras entradas de esta compilación heterogénea (f. 28r) fueron copiadas de un misal de la iglesia de Argentona (Barcelona) del año 1189 y recogen noticias características de la familia de los Barcinonenses desde el ataque de Almanzor

19.- Vid. al respecto Jaime Villanueva, Viage literario a las iglesias de España, vol. 18, Madrid, 1851, p. 125. La noticia de Villanueva (ibid., pp. 123-125) es confusa, porque se refiere a dos manuscritos diferentes como si se tratase de un solo ejemplar. Uno de ellos es el actual Barcelona, Biblioteca de Cataluña, 483, y el otro es el que aquí interesa, que lleva la signatura 485 de esa misma biblioteca. Esto ha producido alguna confusión en la identificación de este códice, como en I. M. PUIG.-M. A. GINER, Index codicològic, cit., $\mathrm{n}^{\mathrm{o}} 72$ (p. 31 y p. 155), donde se lee que todas las noticias de Villanueva se refieren exclusivamente al manuscrito Barcelona, BC, 483.

20.- Editado por É. Baluze, Marca Hispanica, cit., cols. 757-760 (=E. Flórez.-M. Risco, España Sagrada, vol. 28, cit., pp. 334-336). Algunos pasajes fueron editados por Jaime VillanuEVA, Viage literario a las iglesias de España, vol. 15, Madrid, 1851, pp. 214-215 (en algún caso esta edición, aunque fragmentaria, mejora el texto de Baluze). Aparece recogido en RFHMA, vol. 3, p. 463 (con este mismo título).

21.- En efecto, el códice en cuestión no es identificado con ningun ejemplar actual en I. M. PuIG.-M. A. Giner, Índex codicològic, cit., no 738 (p. 133 y p. 169).

22.- Edición de Gabriel Llabrés, "Cronicón de los Dominicos de Mallorca", Bolletí de la Societat Arqueológica Luliana, 12 (1909), pp. 329-331 y 341-344. Llabrés no indica signatura alguna, pero he conseguido identificarlo gracias a la amabilidad de Joana $\mathrm{M}^{\mathrm{a}}$. Bibiloni Antich, facultativa técnica en el Archivo del Reino de Mallorca, que respondió por correo electrónico (04/06/2013) a mi consulta sobre el particular. He dispuesto para su estudio de una reproducción digital completa en color de gran calidad. 
contra Barcelona en 985 hasta la conquista de Siurana de Prades por Ramón Berenguer IV en $1153^{23}$.

\section{LOS CRONICA COMVNIA}

Esta obra se ha conservado en dos manuscritos barceloneses de mediados del siglo XIV, es decir, bastante posteriores a la época de redacción del texto ${ }^{24}$.

1) Barcelona, Archivo Histórico de la Ciudad de Barcelona (AHCB), 1G-9 (olim L-9) (A), conocido como Llibre dels Usatges de Ramón Ferrer o simplemente Usatges de Ramon Ferrer, ff. 34ra-35 $\mathrm{vb}^{25}$. Es un códice formado por cuatro partes bien diferenciadas. La primera (ff. 1r-131v), que es la que aquí interesa, fue ejecutada hacia 1346-1348 en el taller del notario Ramón Ferrer a iniciativa del Consejo de Ciento de la ciudad de Barcelona. El códice no adquirió su forma actual hasta 1365 aproximadamente.

2) Barcelona, AHCB, 1G-10 (olim L-10) (B), conocido como Llibre Verd I, ff. $34 \mathrm{ra}-35 \mathrm{rb}^{26}$. Como el anterior, es un códice formado por varias partes, de las que interesa sólo la primera (ff. 1r-154v y 205r-373r), ejecutada también en el taller de Ramón Ferrer en los mismos años que el volumen precedente, de nuevo por encargo del Consejo de Ciento de Barcelona. El manuscrito quedó completado en un primer momento hacia 1370, pero con posterioridad, aprovechando unos folios en blanco, se añadieron dos documentos del año 1383 (ff. 400r-402v) y casi un siglo después otros dos de los años 1438-1439 (ff. 195r-197v).

El estudio fundamental de Riera Viader y Rovira Solà sobre estos códices defiende que se trata de dos manuscritos ejecutados de manera independiente y simultánea ${ }^{27}$. Ésta es asimismo la impresión que se obtiene de la colación de las dos versiones de los Cronica comunia.

23.- La octava entrada de este cronicón dice así, en efecto (f. 38r): «Transtuli predicta omnia de missali maiori ecclesie loci de Argentona predicacionis Barchin(one), qui scriptus fuerat anno Domini $\mathrm{M}^{\mathrm{o}} \mathrm{CC}^{\mathrm{o}} \mathrm{LXXX}^{\circ} \mathrm{IX}^{\circ} \gg$.

24.- Ambos han sido colacionados a partir de imágenes digitales en color de buena calidad.

25.- Vid. Sebastià Riera Viader.-Manuel Rovira Solà, "Estudio histórico y codicológico", en J. Sobrequés.-S. Riera.-M. Rovira.-T. de Montagut.-J. Yarza, Llibre Verd de Barcelona, vol. 1, cit., pp. 167-214 (="Estudi històric i codicològic", pp. 11-58), en las pp. 192-196 (= pp. 35-39).

26.- Vid. S. Riera.-M. Rovira, "Estudio”, cit., pp. 196-207 (=pp. 40-51). En el manuscrito la foliación se presenta en números romanos.

27.- Por el contrario, para Lucien Barrau Dihigo.-Jaume Massó Torrents, Gesta comitum Barcinonensium. Textos llatí e català, Barcelona, Fundació Concepció Rabell i Cibills, 1925 (Chròniques Catalanes, 2) (reimpr. Barcelona, Institut d'Estudis Catalans, 2007 [Memòries de la Secció HistòricoArqueològica, 79]), pp. LVII-LVIII (Usatges de Ramon Ferrer) y p. LVIII (Llibre Verd I), el texto de los Gesta comitum Barcinonensium del Libre Verd I se habría copiado de los Usatges de Ramon Ferrer. 
En efecto, $A$ no puede haber sido copiado de $B$, pues en la entrada $\mathrm{n}^{\circ}$ 5 el copista de $B$ cometió un error debido a un salto de ojo, pasando de la forma «euangelium» de esa entrada $\mathrm{n}^{\circ} 5$ a la forma correspondiente de la entrada siguiente. Así, frente al texto de $A$ en ese pasaje (f. 28va): "Anno Domini $\mathrm{XL}^{\mathrm{a}}$ Matheus euangelium scripsit. Anno Domini XLIIII ${ }^{\circ}$ Marchus euangelium edidit», en $B$ se lee (f. 34ra): «Anno Domini .XL ${ }^{\circ}$. Matheus euuangelium edidit». A su vez, al menos en otro pasaje $B$ transmite una lectura más correcta que $A$, pues ésta coincide, frente a $A$, con el testimonio de la fuente. Es el siguiente, correspondiente a la entrada $n^{\circ} 4,2$, donde en $B$ se lee (f. 34ra): «Et anno Domini $\mathrm{XXX}^{\circ} \mathrm{II}^{\circ}$ idem Iohannes decollatus est», y en $A$ (f. 28va): «Et anno Domini XXIIII ${ }^{\circ}$ idem Iohannes decollatus est». Sin duda, la variante correcta en este caso es la de $B$, pues es la de la fuente indudable del pasaje, a saber, el Chronicon pontificum et imperatorum de Martín de Opava (†1278/9), que dice así (p. 408,26): «Et anno 19. Iohannes cepit predicare baptismum penitencie. Anno autem 32. idem Iohannes decollatus est» ${ }^{28}$. Es evidente, en consecuencia, que $B$ no ha podido copiarse tampoco de $A$.

Ambos ejemplares contienen un error llamativo en la entrada $\mathrm{n}^{\circ} 12$, pero al tratarse de dos volúmenes ejecutados de forma simultánea en un mismo taller de copia, resulta dudoso si el error estaba ya en el arquetipo o se debe en ambos casos a un error de interpretación de las abreviaturas del original, pues cabe sospechar que pudo haber un intercambio de ideas entre los copistas del citado taller, dado que las manos que copian los Cronica comunia en uno y otro códice parecen diferentes. Esta entrada, fechada en el año 1093 y situada, como le corresponde en virtud de su datación, entre otras relativas a los años 985 y 1100, dice así: «Anno Domini $\mathbf{M}^{\circ} \mathbf{X C I I}^{\circ}$, kalendas marcii, fuit interfectus dominus Berengarius Tarrachonensis archiepiscopus, Arnaldus Guillelmi et Raymundus Montischateni in Valencia». Es evidente que la noticia, incomprensible en buena medida en la versión de estos manuscritos, se refiere al asesinato del arzobispo de Tarragona Berenguer de Vilademuls en 1194 a manos de Guillermo Ramón de Moncada, luego vizconde de Bearn como Guillermo $\mathrm{I}^{29}$. La solución del pasaje puede deducirse fácilmente a partir del

28.- Cito por la edición de Ludwig WeILAnd, "Martini Oppaviensis Chronicon pontificum et imperatorum", Monumenta Germaniae Historica, Scriptores XXII, Hannover, Monumenta Germaniae Historica, 1872, pp. 377-482 (introducción en las pp. 377-397 y edición en las pp. 397-482). Sobre Martín de Opava y su cronicón, vid. RFHMA, vol. 7, pp. 489-490 ("Martinus Oppaviensis"); Anna-Dorothee von den Brincken, "Martin de Opava", The Encyclopedia of the Medieval Chronicle, cit., vol. 2, pp. 1085-1088.

29.- Sobre el episodio, vid. en especial Miquel Coll Alentorn, “Aperçu de l'histoire politique des Pays Catalans au XIIe siècle", Les Cahiers de Saint-Michel de Cuxa, 4 (1973), pp. 9-18, en las pp. 15-16. Sobre los dos personajes implicados, vid. Manuel Fuentes Gasó, "Vilademuls, Berenguer de", 
texto de los Annales Barcinonenses a. 1323 de Madrid, BN, 18060, donde se lee esta misma noticia así, en el f. $138 \mathrm{v}$ : «Anno domini $\mathrm{M}^{\circ} \mathrm{XCIII}{ }^{\circ} \mathrm{kls}$. marcii fuit interfectus dns. Berengarius Tarrachone archiepiscopus a $\mathrm{G}^{\circ}$. R. montischateni in Vallen.». Vemos, entonces, que el error de la datación remonta con toda probabilidad al arquetipo, pero no el error que afecta al resto de la entrada. Evidentemente la construcción del ablativo agente con la preposición «a» fue reinterpretado como la inicial de «Arnaldus» por un copista que no sabía demasiado latín ni conocía, por supuesto, los hechos históricos, y de ese modo el ablativo agente «a $\mathrm{G}^{\circ}$.» («a Guillelmo») se transformó en el nominativo «Arnaldus Guillelmus». Además, al final de la noticia la abreviatura «Vallen.» se interpretó como «Valencia», cuando, en realidad, habría debido ser transcrita como «Vallensi»o «Vallense».

Otro error común de ambos manuscritos se lee en la entrada $n^{\circ}$ 9,2: «iuxta palacium Neromanum», donde hay que entender, tal y como se lee en la fuente: «iuxta palacium Neronianum» ${ }^{30}$. $\mathrm{Y}$ otros muchos errores afectan a las dataciones de las noticias recogidas en esta pequeña crónica, lo que hace sospechar que el arquetipo estaba ya plagado de ellos.

Por lo que se refiere a las fuentes del texto, el autor de los Cronica comunia se sirvió ampliamente del Chronicon pontificum et imperatorum de Martín de Opava. Esta obra es la fuente de las entradas $n^{\circ} 1-10, n^{\circ} 25-26$ y, probablemente, $\mathrm{n}^{\mathrm{o}} 39$ del cronicón barcelonés (de esta última sólo parcialmente).

Veamos algunos ejemplos:

DHEC, vol. 3, pp. 677-678, y Pierre Tucoo-Chala, Quand l'Islam était aux portes des Pyrénées: De Gaston IV le Croisé à la croisade des Albigeois (XIe-XIIIe siècles), Biarritz, J\&D Éditions, 1994 (Terres et hommes du sud), en las pp. 240-242 (Guillermo Ramón de Moncada).

30.- Martín de Opava, Chronicon pontificum et imperatorum, p. 409,30. 


\section{Cronica comunia}

2. ${ }^{1}$ Anno eodem quo Christus natus fuit, tulit eum Iosep in Egiptum. ${ }^{2}$ Quo ingrediente, corruerunt idola Egipti iuxta uaticinium Ysaye. ${ }^{3}$ Et sicut traditur, non fuit in Egipto templum in quo non corruisset ydolum. ${ }^{4} \mathrm{Et}$ in $\mathrm{VII}^{\circ}$ anno a natiuitate sua de Egipto reuertitur in Iudeam.

7. Post passionem Domini, regnante Tiberio imperatore, Poncius Pilatus propter multas acusaciones contra ipsum factas a dicto Tiberio in exilium Viennam Burgundie mittitur et propter multas calamitates, quas ibidem sustinuit, se propria manu interfecit.

9. ${ }^{1}$ Passi sunt apostoli Petrus et Paulus ultimo anno Neronis crudelissimi imperatoris: Petrus quidem in uia Aurelia ibique sepultus iuxta palacium Neromanum in Vaticano, ubi crucifixus est; Paulus uero ad Aquas Saluias in uia Hostiensi fuit decapitatus. ${ }^{2}$ Tempore autem Cornelii pape Greci furati sunt corpora dictorum apostolorum et, ut ipsa in Greciam deferrent, secum asportabant. ${ }^{3}$ Set demones in Rome ydolis habitantes diuina coacti uirtute clamabant: Viri Romani, succurrite, quia dii uestri auferuntur! ${ }^{4}$ Ffideles hoc intelligentes de apostolis, infideles uero de suis diis, multitudo adunata fidelium et infidelium, illos persecuntur. ${ }^{5} \mathrm{Quod}$ uidentes Greci apud cathacumbas apostolorum corpora in puteum proiecerunt, set a beato Cornelio papa fuerunt inde abstracta. ${ }^{6}$ Set cum in dubium uerteretur que essent ossa Petri et que Pauli, orantibus fidelibus et ieiunantibus, diuinitus responsum habuerunt quod maiora ossa sunt predicatoris, minora uero piscatoris. ${ }^{7}$ Que tamen post beatus Siluester dicitur cum lante equaliter ponderasse et consecrando utriusque ecclesiam in utraque utriusque ossa collocasse.

25. ${ }^{1}$ Anno Domini $\mathrm{M}^{\circ} \mathrm{CXCVIII}^{\circ}$ ordinem fratrum Predicatorum incepit sanctus Dominicus in partibus Tholosanis, ubi contra hereticos uerbo et exemplo predicabat. ${ }^{2} \mathrm{Qui}$

\section{Chronicon pontificum et imperatorum}

p. 408,27-29: Eodem anno, quo natus est, tulit eum Ioseph in Egiptum. Quo ingrediente corruerunt ydola Egypti iuxta uaticinium Ysaye. Et sicut traditur, non fuit in Egypto templum in quo non corruiset ydolum. Et in 7. anno a natiuitate sua de Egypto reuertitur in Iudeam.

p. 444,22-24: Post passionem Domini dictus Tyberius imperator imperavit annis 5. Poncius Pilatus propter multas accusaciones contra ipsum factas a Tyberio in exilium Viennam Burgundie mittitur et propter multas calamitates, quas ibidem sustinuit, se propria manu interfecit.

p. 409,29-40: Passi sunt autem Petrus et Paulus ultimo anno Neronis: Petrus quidem in via Aurelia ibique sepultus iuxta palacium Neronianum in Vaticano ubi crucifixus est, Paulus uero ad aquas Salvias in via Hostiensi. Tempore autem Cornelii pape Greci furati corpora sanctorum apostolorum, ut ipsa in Greciam deferrent, asportabant. Sed demones habitantes in ydolis divina coacti virtute clamabant: Viri Romani, succurrite, quia dii vestri auferuntur. Fideles hoc intelligentes de apostolis, infideles uero de suis diis, multitudo adunata fidelium et infidelium illos persequitur. Quod uidentes Greci apud cathacumbas apostolorum corpora in puteum proiecerunt. Sed a beato Cornelio papa sunt inde extracta. Sed cum in dubium verteretur, que essent ossa Petri vel Pauli, orantibus fidelibus et ieiunantibus, divinitus responsum habuerunt, quod maiora ossa sunt predicatoris, minora vero piscatoris. Que tamen post beatus Silvester dicitur cum lance equaliter ponderasse et consecrando utriusque ecclesiam in utraque utriusque ossa collocasse.

p. $438,40-41+$ p. $439,28-30:$ « Ordinem fratrum Predicatorum incepit sanctus Dominicus in Tolosanis partibus, ubi contra hereticos uerbo et exemplo predicabat, anno 
deffunctus est et sepultus Bononie anno conuersionis sue $\mathrm{XVIII}{ }^{\circ}$.

26. ${ }^{1}$ Anno Domini $\mathrm{M}^{\mathrm{o}} \mathrm{CC}^{\mathrm{o}} \mathrm{VI}^{\mathrm{o}}$ incepit sanctus Franciscus ordinem fratrum Minorum prope ciuitatem Assissii apud Sanctam Mariam de Porciuncula. ${ }^{2}$ Qui anno XXIIII ${ }^{\circ}$ conuersionis sue defunctus est et nominabatur ante suam conuersionem Iohannes.

39. Anno Domini $\mathrm{M}^{\circ} \mathrm{CC}^{\circ} \mathrm{LXVIII}{ }^{\circ}$, kalendas decembris, obiit Clemens IIII $^{\mathrm{us}}$ papa, seruus Dei, qui prius uocabatur Guido Folquix, nacione Prouincialis, et duxerat uxorem et habuerat prolem, postea fuit archiepiscopus Narbonensis, postea cardinalis Sabinensis, ad ultimum uocatus fuit ad summum pontificem et sedit in pontificatu annis tribus, mensibus nouem, diebus uiginti et uno.
Domini 1198... Hic Reate beatum Dominicum, inuentorem et magistrum ordinis Predicatorum, Bononie sepultum et miraculis innumeris coruschantem canonizauit anno Domini 1233, a confirmacione ordinis anno 18, a morte eius anno 11. »

p. 438,42-45: « Ordinem uero fratrum Minorum incepit sanctus Franciscus prope ciuitatem Assisinam apud Sanctam Maria de Porciuncula, anno Domini 1206, pontificatus eiusdem domini Innocencii anno 14, qui fuit annus conversionis ipsius, a quo post 24. anno defunctus est. Qui Franciscus ante suam conuersionem uocabatur Iohannes. »

p. 441,3+441,6-8 : «Clemens nacione Provincialis de villa Sancti Egidii sedit annis 3 , mensibus 9, diebus 21... Hic uxorem et liberos habens, primum fuit famosus advocatus et regis Francie consiliarius. Deinde mortua uxore propter vitam et scienciam laudabilem primo Podiensis episcopus et post Narbonensis archiepiscopus, tandem Sabinensis episcopus (add. et Cardinalis C) efficitur. »

Es interesante observar cómo en la entrada $\mathrm{n}^{\circ} 25,2$ el autor de los Cronica comunia ha cometido un error de interpretación de la fuente. Así, escribe: «Qui deffunctus est et sepultus Bononie anno conuersionis sue XVIII ${ }^{\circ}$ », afirmando que Domingo de Guzmán murió en el año 1233, el decimoctavo desde la fundación de la orden de los Predicadores (a. 1215), mientras que la fuente atribuye al año 1233 no la muerte del santo, sino su canonización, doce años después, en realidad, del fallecimiento de Domingo de Guzmán $(\dagger 6 . \text { VIII.1221) })^{31}$.

Por otro lado, el uso del cronicón de Martín de Opava apunta al a. 1276 como terminus post quem de redacción de los Cronica comunia. En efecto, de acuerdo con el estudio de la tradición manuscrita de la obra de Martín de Opava efectuado por el editor del texto, ésta se ha conservado en tres grandes recensiones: $\mathrm{A}, \mathrm{B}$ y $\mathrm{C}^{32}$. De ellas, $\mathrm{B}$ representa la última versión del autor y puede fecharse hacia 1268/71. Mientras que la recensión C sería el resultado 
de adiciones incorporadas por distintos autores y se habría completado hacia 1276, pues incluye, además de una serie de añadidos a lo largo del texto, una continuación en las noticias dedicadas a los papas de Roma que concluye con Inocencio V $(† 22 . V I .1276)$. Y es precisamente esta recensión C la que manejó el autor de los Cronica comunia. Lo prueba el hecho de que las entradas dedicadas a Domingo de Guzmán y Francisco de Asís (nº 25-26) están basadas en sendas adiciones del cronicón de Martín de Opava propias de la recensión $\mathrm{C}^{33}$.

Conviene añadir al final de esta presentación del texto que los Cronica comunia siguen el sistema de datación habitual en la Cataluña medieval de los siglos XII-XIV en el que el nuevo año no empieza hasta el 25 de marzo, festividad de la Anunciación (entradas no 29-30, 33) ${ }^{34}$.

\section{EDICIÓN CRÍTICA ${ }^{35}$}

Ofrezco a continuación la editio princeps de los Cronica comunia. Tomo como testimonio fundamental la versión conservada en $A$, que en general es más correcta que la de $B$. Numero las entradas de acuerdo con lo que parece ser la idea original del autor. En efecto, si bien en los dos manuscritos el texto aparece copiado sin distinción de entradas, en ambos se marcan de forma especial una serie de mayúsculas, escritas en un tamaño mayor y en color (rojo y azul de forma alternativa en los dos códices) frente al uso general de la tinta negra empleada para copiar el resto de la crónica. He seguido estas marcas a la hora de distribuir el texto en cuarenta entradas. Numero además cada una de las oraciones de las entradas para facilitar la forma de cita. El título es el mismo en los dos códices.

33.- Vid. L. WeILAnd, "Martini Oppaviensis", cit., p. 438, nota y) del aparato crítico. Según A.-D. von de BRINCKEN, "Martin de Opava", cit., p. 1086, la recensión B es de hacia 1272 y la C de hacia 1277.

34.- Sobre el origen de este sistema (denominado florentino) en Cataluña, vigente desde octubre de 1180 hasta comienzos de 1351, vid. Ascari Manuel Mundó, "El concili de Tarragona de 1180: dels anys dels reis francs als de l'encarnació", Analecta Sacra Tarraconensia, 67/1 (1994), pp. XXIII-XLIII; y sobre todo, Jaime BAUCELls ReIG, "La cronologia a Catalunya en general i a Barcelona en particular", en Calligraphia et tipographia. Arithmetica et numerica. Chronologia, Barcelona, Universitat de Barcelona, 1998 (Rubrica. Palaeographica et Diplomatica Studia, 7), pp. 7-99, en las pp. 22-38.

35.- Siglas utilizadas en los manuscritos: $A=$ Barcelona, AHCB, 1G-9 (olim L-9) (Usatges de Ramon Ferrer), f. 28ra-vb; $B=$ Barcelona, AHCB, 1G-10 (olim L-10) (Llibre Verd I), ff. 34ra-35vb. Siglas utilizadas en el aparato de fuentes: Mart. Opp. chron. = Martín de Opava, Chronica siue Chronicon pontificum et imperatorum, ed. L. WeILAnd, Monumenta Germaniae Historica, cit., pp. 397-482. 


\section{Cronica comunia}

1. Fuerunt ab Adam usque ad natiuitatem Christi completi anni v mille CXCIX.

2. ${ }^{1}$ Anno eodem quo Christus natus fuit, tulit eum Ioseph in Egiptum. ${ }^{2}$ Quo ingrediente, corruerunt idola Egipti iuxta uaticinium Ysaye. ${ }^{3} \mathrm{Et}$ sicut traditur, non fuit in Egipto templum in quo non corruisset ydolum. ${ }^{4} \mathrm{Et}$ in $\mathrm{VII}^{\circ}$ anno a natiuitate sua de Egipto reuertitur in Iudeam.

3. Anno Domini XvII Pilatus factus est preses in Iudea.

4. ${ }^{1}$ Anno Domini $\mathrm{XIX}^{\circ}$ Iohannes babtista cepit predicare babtismum penitencie. ${ }^{2} \mathrm{Et}$ anno Domini $\mathrm{XXX}^{\circ} \mathrm{II}^{\mathrm{o}}$ idem Iohannes decollatus est.

5. Anno Domini $\mathrm{XL}^{\circ}$ Matheus euangelium scripsit.

6. Anno Domini XLIIII ${ }^{\circ}$ Marchus euangelium edidit.

7. Post passionem Domini, regnante Tiberio imperatore, Poncius Pilatus propter multas acusaciones contra ipsum factas a dicto Tiberio in exilium Viennam Burgundie mittitur et propter multas calamitates, quas ibidem sustinuit, se propria manu interfecit.

8. Herodes, qui Iohannem babtistam occiderat et sub quo passus est Christus, cum Herodiade uxore sua apud Viennam in exilio mittitur ibique ambo miserabiliter moriuntur.

9. ${ }^{1}$ Passi sunt apostoli Petrus et Paulus ultimo anno Neronis crudelissimi imperatoris: Petrus quidem in uia Aurelia ibique sepultus iuxta palacium Neromanum in Vaticano, ubi crucifixus est; Paulus uero ad Aquas Saluias in uia Hostiensi fuit decapitatus. ${ }^{2}$ Tempore autem Cornelii pape Greci furati sunt corpora dictorum apostolorum et, ut ipsa in Greciam deferrent, secum asportabant. ${ }^{3}$ Set demones in Rome ydolis habitantes diuina coacti uirtute clamabant: Viri Romani, succurrite, quia dii uestri auferuntur! ${ }^{4}$ Ffideles hoc intelligentes de apostolis, infideles uero de suis diis, multitudo adunata fidelium et infidelium, illos persecuntur. ${ }^{5} \mathrm{Quod}$ uidentes Greci apud cathacumbas apostolorum corpora in puteum proiecerunt, set a beato Cornelio papa fuerunt inde abstracta. ${ }^{6}$ Set cum in dubium uerteretur que essent ossa Petri et que Pauli, orantibus fidelibus et ieiunantibus, diuinitus responsum habuerunt quod maiora ossa sunt predicatoris, minora uero piscatoris. ${ }^{7} \mathrm{Que}$ tamen post beatus Siluester dicitur cum lante equaliter ponderasse et consecrando utriusque ecclesiam in utraque utriusque ossa collocasse.

10. Anno $\mathrm{VI}^{\mathrm{o}}$ dicti Neronis imperatoris Senecha Cordubensis, patruus Lucani poete, preceptor Neronis, uita et sciencia preclarus, incisione uene et haustu ueneni iussu Neronis periit.

11. Anno Domini DCCCCLXXv ${ }^{\circ}$, kalendas iulii, regnante Lotario rege Franchorum, fuit obcessa ciuitas Barchinone a paganis et fuerunt interfecti quingenti milites cum Borrello comite in Vallense, in loco qui dicitur Ruuiranus, et eorum capita adduxerunt apud Barchinonam et cum fundibulo proiecerunt in platea ante ecclesiam sanctorum Iusti et Pastoris et eadem die capta fuit ciuitas.

12. Anno Domini $\mathbf{M}^{\mathrm{o}} \mathrm{XCII}{ }^{\circ}$, kalendas marcii, fuit interfectus dominus Berengarius Tarrachonensis archiepiscopus, Arnaldus Guillelmi et Raymundus Montischateni in Valencia.

13. Anno Domini $\mathbf{M}^{\circ} \mathrm{C}^{\circ}$ minus uno anno ceperunt christiani ciuitatem Iherusalem. 
14. Anno $\mathrm{M}^{\mathrm{O}} \mathrm{CI}^{\mathrm{O}}$ decessit dominus Raymundus comes de Sancto Egidio.

15. Anno Domini $\mathrm{M}^{\circ} \mathrm{CIX}^{\circ}, \mathrm{XII}^{\circ}$ die aprilis, incepit domus de Cistella.

16. Anno Domini $\mathrm{M}^{\circ} \mathrm{CXIII}^{\circ}$, kalendas februarii, capta fuit ciuitas Maioricarum.

17. Anno Domini $\mathrm{M}^{\circ} \mathrm{C}^{\circ} \mathrm{XXXV}^{\circ}$ obiit Ollegarius episcopus Barchinonensis et Tarrachonensis archiepiscopus.

18. Anno Domini $\mathrm{M}^{\circ} \mathrm{CXLVII}{ }^{\circ}$ capta fuit ciuitas Almarie a Raymundo Berengarii comite $\mathrm{VI}^{\mathrm{o}}$ kalendas nouembris.

19. Anno Domini $\mathrm{M}^{\circ} \mathrm{CXLVIII}^{\circ}$, pridie kalendas ianuarii, capta fuit ciuitas Dertuse a domino Raymundo Berengarii comite.

20. Anno Domini $\mathbf{M}^{\circ} \mathrm{CXLIX}^{\circ}$, kalendas nouembris, fuerunt capte ciuitas Ilerde et uilla Frage a proxime dicto comite.

21. Anno Domini $\mathrm{M}^{\circ} \mathrm{CLIIII}{ }^{\circ}, \mathrm{vI}^{\circ}$ kalendas decembris, fuit capta Ciurana a predicto domino comite.

22. ${ }^{1}$ Anno Domini $\mathrm{M}^{\circ} \mathrm{CLXVII}{ }^{\circ}$, VIII ${ }^{\circ}$ idus augusti, obiit Raymundus Berengarii comes Barchinone, princeps Aragonum et marchio Prouincie. ${ }^{2}$ Qui claustra Yspanie fregit ac ciuitates Almarie et Deroche, Ilerde, Dertuse et Frage et omnia que sunt citra flumen Yberis cepit. sim.

23. Anno Domini $\mathrm{m}^{\circ} \mathrm{CLXXX}{ }^{\circ}$, idus septembris, sol passus fuit eclip-

24. Anno Domini $\mathrm{M}^{\circ} \mathrm{CLXXX}^{\circ} \mathrm{VIII}^{\circ}, \mathrm{VI}^{\circ}$ nonas octobris, capta fuit ciuitas Iherusalem.

25. ${ }^{1}$ Anno Domini $\mathrm{M}^{\circ} \mathrm{CXCVIII}^{\circ}$ ordinem fratrum Predicatorum incepit sanctus Dominicus in partibus Tholosanis, ubi contra hereticos uerbo et exemplo predicabat. ${ }^{2}$ Qui deffunctus est et sepultus Bononie anno conuersionis sue $\mathrm{XVIII}^{\circ}$.

26. ${ }^{1}$ Anno Domini $\mathrm{M}^{\mathrm{o}} \mathrm{CC}^{\mathrm{o}} \mathrm{VI}^{\mathrm{o}}$ incepit sanctus Franciscus ordinem fratrum Minorum prope ciuitatem Assissii apud Sanctam Mariam de Porciuncula. ${ }^{2}$ Qui anno XXIIII ${ }^{\circ}$ conuersionis sue defunctus est et nominabatur ante suam conuersionem Iohannes.

27. Anno Domini $\mathrm{M}^{\circ} \mathrm{CC}^{\circ} \mathrm{XI}^{\circ}$ fuit interfectus Petrus de Serrato episcopus Barchinonensis.

28. Anno Domini $\mathrm{M}^{\circ} \mathrm{CC}^{\circ} \mathrm{XII}^{\circ}, \mathrm{XVII}^{\circ}$ kalendas augusti, factum fuit prelium inter paganos et christianos apud Vbedam et eodem anno $\mathrm{XII}^{\circ}$ kalendas augusti fuit capta ciuitas Vbede.

29. Anno Domini $\mathrm{M}^{\circ} \mathrm{CC}^{\circ} \mathrm{XII}^{\circ}, \mathrm{XI}^{\circ}$ kalendas aprilis, fuit aspersa moneta de quaterno a domino rege Petro.

30. Anno Domini $\mathrm{M}^{\circ} \mathrm{CC}^{\circ} \mathrm{XXI}^{\circ}, \mathrm{x}^{\circ}$ kalendas marcii, fuit aspersa moneta de duplencho a domino Iacobo rege Aragonum.

31. Anno Domini $\mathrm{M}^{\circ} \mathrm{CC}^{\circ} \mathrm{XXIII}^{\circ}$, nonas nouembris, capta fuit Damiata a paganis.

32. Anno Domini $\mathrm{M}^{\circ} \mathrm{CC}^{\circ} \mathrm{XXV}^{\circ}$, pridie idus septembris, iuit dominus Tarrachonensis archiepiscopus cum suo exercitu ad insulam Euiçe et eodem anno quinto idus augusti cepit castrum de Euiça.

33. Anno Domini $\mathrm{M}^{\circ} \mathrm{CC}^{\circ} \mathrm{XXV}^{\circ}$ mensibus ianuarii, februarii et marcii fuit uendita in Barchinona quarteria frumenti LVI solidis et quarteria ordei XL solidis. 
34. ${ }^{1}$ Anno Domini $\mathrm{M}^{\circ} \mathrm{CC}^{\circ} \mathrm{XXXVI}^{\circ}$, idus septembris, illustris dominus Iacobus rex Aragonum cum comitibus et aliis multis nobilibus de terra sua aplicauit ad insulam Maioricarum cum ducentis triginta tribus uelis et factum fuit ibi campestre bellum inter christianos et sarracenos et fuit ibi interfectus Guillelmus de Montecatheno cum XXIIII militibus. ${ }^{2} E t$ eodem anno pridie kalendas ianuarii fuit capta ciuitas Maioricarum a domino rege prefato.

35. Anno Domini $\mathrm{M}^{\circ} \mathrm{CC}^{\circ} \mathrm{XXXVI}^{\circ}$ fuit capta uilla de Burriana a dicto domino rege Iacobo.

36. Anno Domini $\mathrm{M}^{\circ} \mathrm{CC}^{\circ} \mathrm{XXXVIII}{ }^{\circ}, \mathrm{IIII}^{\circ}$ kalendas octobris, fuit capta ciuitas Valencie a dicto domino rege Iacobo et in sequenti anno III $^{\circ}$ nonas iulii sol passus est eclipsim hora $\mathrm{VI}^{\mathrm{a}}$.

37. Anno Domini $\mathrm{M}^{\circ} \mathrm{CC}^{\circ} \mathrm{LXVI}^{\circ}$ Karolus, frater Ludouici regis Francie, comes Prouincie, cepit Apuliam, Calabriam et Ciciliam et deuicit in campo apud Beneuentum Matfredum regem Cicilie.

38. Anno Domini $\mathrm{M}^{\circ} \mathrm{CC}^{\circ} \mathrm{LXVIII}{ }^{\circ}$, $\mathrm{IIII}^{\circ}$ nonas augusti, dominus rex Iacobus fecit fieri uelum ut iret ultramare et reuersus est IIII $^{\circ}$ nonas septembris in Aquis mortuis.

39. Anno Domini $\mathrm{M}^{\circ} \mathrm{CC}^{\circ} \mathrm{LXVIII}^{\circ}$, kalendas decembris, obiit Clemens IIII ${ }^{\mathrm{us}}$ papa, seruus Dei, qui prius uocabatur Guido Folquix, nacione Prouincialis, et duxerat uxorem et habuerat prolem, postea fuit archiepiscopus Narbonensis, postea cardinalis Sabinensis, ad ultimum uocatus fuit ad summum pontificem et sedit in pontificatu annis tribus, mensibus nouem, diebus uiginti et uno.

40. Anno Domini $\mathrm{M}^{\circ} \mathrm{CC}^{\circ} \mathrm{LXX}^{\circ}$ fecit fieri uelum in Aquis mortuis contra sarracenos Ludouicus, Dei gracia rex Francorum, $\mathrm{VI}^{\circ}$ nonas iulii et aplicuit Tunicium cum filiis suis et uxoribus filiorum suorum et nono kalendas augusti cepit Cartaginem et ibi mortuus est in pace.

Apparatus criticus

2,1. ioseph : iosep $A .2,2$. post corruerunt $a d d$. ydo $B^{1} .4,1$. XIX ${ }^{\circ}$ : XXIX $B^{2} .4,2 . \mathrm{XXX}^{\circ} \mathrm{II}^{\mathrm{o}} A$ (cum fonte), $\mathrm{XXIII}^{\circ} B \cdot 5 \cdot \mathrm{XL}^{\circ}: \mathrm{XL}^{\mathrm{a}} A . \|$ euangelium : euuangelium $B$. II scripsit $o m$. $B$. 6. anno domini XLIIII ${ }^{\circ}$ marchus euangelium om. B. 7. tiberio ${ }^{1}$ : tyberio $B$. $\|$ acusaciones : accusaciones $B$. $\|$ tiberio $^{2}$ : thiberio $B$. 9,1. et: e $B^{l}$. II palacium : palatium $B$. II neromanum : neronianum intellege cum fonte. 9,2. deferrent : defferrent $B$. 9,3. auferuntur : aufferuntur $B$. 9,4. persecuntur $A$ (cum fonte), prosecuntur $B$. 9,7. lante : lance intellege. 11. DCCCCLXXXv ${ }^{\circ}$ : DCCCCLXXXV A. Il lotario : lothario $B$. II obcessa : obsessa intellege. II post borrello add. milite $B^{l}$. II proiecerunt: proiescerunt $B^{2}$. 12. montischateni : montiscatheni $B .15 . \mathrm{M}^{\circ} \mathrm{CIX}^{\mathrm{o}}: \mathrm{M}^{\mathrm{o}} \mathrm{C}^{\mathrm{o}} \mathrm{IX}$ $B$. II cistella scripsi, cistell. codd. 16. februarii : febroarii $B$. II maioricarum scripsi, maioric. codd. $17 . \mathrm{M}^{\circ} \mathrm{C}^{\circ} \mathrm{XXXV}^{\circ}: \mathrm{M}^{\circ} \mathrm{CXXXV}^{\circ}$ B. 18. almarie : almaue $B .19 . \mathrm{M}^{\circ} \mathrm{CXLVIII}^{\circ}: \mathrm{M}^{\circ} \mathrm{CXLVIII} B .20 . \mathrm{M}^{\circ} \mathrm{CXLIX}^{\circ}: \mathrm{M}^{\circ} \mathrm{CXLIX} B .21$. $\mathrm{M}^{\circ} \mathrm{CLIIII}{ }^{\circ}: \mathrm{M}^{\circ} \mathrm{C}^{\circ} \mathrm{LIIII}^{\circ} B$. $\|$ ciurana : siurana $B .22 . \mathrm{M}^{\circ} \mathrm{CLXVII}{ }^{\circ}: \mathrm{M}^{\circ} \mathrm{C}^{\circ} \mathrm{LX}^{\circ} \mathrm{VII}^{\circ} B$. 23. $\mathrm{M}^{\circ} \mathrm{CLXXX}^{\circ}: \mathrm{M}^{\circ} \mathrm{C}^{\circ} \operatorname{LXXX}^{\circ} B .24 . \mathrm{M}^{\circ} \mathrm{CLXXX}{ }^{\circ} \mathrm{VIII}^{\circ}: \mathrm{M}^{\circ} \mathrm{C}^{\circ} \operatorname{LXXX}^{\circ} \mathrm{VIII}^{\circ} B .25, \mathrm{I}$ $\mathrm{M}^{\circ} \mathrm{CXCVIII}^{\circ}: \mathrm{M}^{\circ} \mathrm{CXC}^{\circ} \mathrm{VIII}{ }^{\circ} B .25,2$. deffunctus : defunctutus $B$. 26. franciscus $B$ (cum fonte), francischus $A$. II porciuncula $B$ (cum fonte), portiuncula A. 27. $\mathrm{M}^{\circ} \mathrm{CC}^{\circ} \mathrm{XI}^{\circ}: \mathrm{M}^{\circ} \mathrm{CC}^{\circ} \mathrm{XI} A$. II barchinonensis scripsi, barchn. codd. 28. $\mathrm{M}^{\circ} \mathrm{CC}^{\circ} \mathrm{XII}^{\circ}$ : millesimo $\mathrm{CC}^{\circ} \mathrm{XII}^{\circ} B .31 . \mathrm{M}^{\circ} \mathrm{CC}^{\circ} \mathrm{XXIII}^{\circ}$ : millesimo $\mathrm{CC}^{\circ} \mathrm{XXIII}^{\circ} B$. 
LOS CRONICA COMVNIA: UNA CRÓNICA LATINA DE ORIGEN BARCELONÉS DEL SIGLO XIII.

33. februarii : febroarii $B .34,1 . \mathrm{M}^{\circ} \mathrm{CC}^{\mathrm{o}} \mathrm{XXXVI}^{\mathrm{o}}: \mathrm{M}^{\mathrm{o}} \mathrm{CCXXX}^{\circ} \mathrm{VI}^{\mathrm{o}} B$. Il septembris : septenbris $B$. II maioricarum scripsi, maioric. codd. II montecatheno : monthecatheno $B .34,2$. fuit : ffuit $B$. II maioricarum scripsi, maioric. codd. 35. $\mathrm{M}^{\circ} \mathrm{CC}^{\circ} \mathrm{XXXVI}^{\circ}: \mathrm{M}^{\mathrm{o}} \mathrm{CC}^{\mathrm{o}} \mathrm{XXX}^{\mathrm{o}} \mathrm{VI}^{\mathrm{o}} B \cdot 36 . \mathrm{M}^{\mathrm{o}} \mathrm{CC}^{\mathrm{o}} \mathrm{XXXVIII}^{\mathrm{o}}: \mathrm{M}^{\mathrm{o}} \mathrm{CC}^{\mathrm{o}} \mathrm{XXX}^{\mathrm{o}} \mathrm{VIII}^{\mathrm{o}} B$. 36. rege iacobo : iacobo rege $B$. 37. $\mathrm{M}^{\circ} \mathrm{CC}^{\circ} \mathrm{LXVI}^{\circ}$ : millesimo $\mathrm{CC}^{\circ} \mathrm{LXVI}^{\circ} B$. ॥ matfredum : matffredum $B .38 . \mathrm{M}^{\circ} \mathrm{CC}^{\circ} \mathrm{LXVIII}{ }^{\circ}$ : millesimo $\mathrm{CC}^{\circ} \mathrm{LX}^{\circ} \mathrm{VIII}^{\circ} B . \|$ ultramare : ultra mare $B .39 . \mathrm{M}^{\circ} \mathrm{CC}^{\circ} \mathrm{LXVIII}^{\circ}: \mathrm{M}^{\circ} \mathrm{CC}^{\circ} \mathrm{LX}^{\circ} \mathrm{VIII}{ }^{\circ} B \cdot 40 . \mathrm{M}^{\circ} \mathrm{CC}^{\circ} \mathrm{LXX}^{\circ}$ : millesimo $\mathrm{CC}^{\mathrm{o}} \mathrm{LXX} \mathrm{X}^{\mathrm{o}} B$. II nono : $\mathrm{IX}^{\mathrm{o}} B$.

Fontes

1. Biblia

2. corruerunt - ysaye : cfr Is. 2,18.

2. Auctores antiquiores

1 fuerunt - CXCIX : Mart. Opp. chron. p. 408,20-21. 2. anno - iudeam : Mart. Opp. chron. p. 408,27-29. 3. anno - iudea : Mart. Opp. chron. p. 408,25. 4. anno $^{1}$ - est : Mart. Opp. chron. p. 408,26. 5. anno - scripsit : Mart. Opp. chron. p. 409,5. 6. anno - edidit : Mart. Opp. chron. p. 409,5. 7. post - interfecit : Mart. Opp. chron. p. 444,22-24. 8. herodes - moriuntur : Mart. Opp. chron. p. 444,24-26. 9. passi - collocasse : Mart. Opp. chron. p. 409,29-40. 10. anno - periit : Mart. Opp. chron. p. 445,2-3. 25,1. anno - predicabat : Mart. Opp. chron. p. 438,40-41. 25,2. qui - XVIII ${ }^{\circ}$ : Mart. Opp. chron. p. 439,28-30. 26. anno - iohannes : Mart. Opp. chron. p. 438,42-45. 39. nacione prouincialis ... sedit - uno : Mart. Opp. chron. p. 441,3. II duxerat - sabinensis : Mart. Opp. chron. p. 441,6-8.

\section{TRAducción ANOTADA}

\section{Crónica general}

1. Transcurrieron desde Adán hasta el nacimiento de Cristo 5199 años.

2. El mismo año en que Cristo nació, José lo llevó a Egipto. Al entrar aquél allí, los ídolos de Egipto se vinieron abajo según la profecía de Isaías. Y según se cuenta, no hubo en Egipto un solo templo en el que el ídolo no se viniese abajo. Y el séptimo año después de su nacimiento regresa a Judea.

3. En el año del Señor 17 Pilatos fue nombrado prefecto en Judea.

4. En el año del Señor 19 Juan el Bautista comenzó a predicar el bautismo de la penitencia. Y en el año del Señor 24 este mismo Juan fue decapitado.

5. En el año del Señor 40 Mateo escribió su evangelio.

6. En el año del Señor 43 Marcos publicó su evangelio.

7. Después de la pasión del Señor, durante el reinado del emperador Tiberio, Poncio Pilatos fue enviado al exilio a Vienne de Burgundia por el citado Tiberio debido a las numerosas acusaciones vertidas contra él y, debido a las muchas penalidades que allí soportó, se dio muerte con su propia mano. 
8. Herodes ${ }^{36}$, que había hecho matar a Juan el Bautista y bajo el que Cristo padeció la pasión, es enviado al exilio a Vienne junto a su esposa Herodías y allí ambos mueren de forma miserable.

9. Padecieron la pasión los apóstoles Pedro y Pablo el último año del crudelísimo emperador Nerón: Pedro, en efecto, en la vía Aurelia y allí fue sepultado junto al palacio de Nerón en el Vaticano, donde fue crucificado; Pablo, por su parte, fue decapitado en la vía Ostiense junto a Aquae Salviae. A continuación, en tiempos del papa Cornelio ${ }^{37}$, unos griegos robaron los cuerpos de los citados apóstoles y los llevaban consigo para transportarlos a Grecia. Pero los demonios que habitaban en el interior de los ídolos de Roma, forzados por el poder de Dios, comenzaron a gritar: "iVarones romanos, acudid rápidamente, pues vuestros dioses están siendo robados!”. Los griegos, al ver esto, arrojaron los cuerpos de los apóstoles dentro de un pozo en las catacumbas, pero fueron sacados de allí por orden del bienaventurado papa Cornelio. Y puesto que era dudoso cuáles eran los huesos de Pedro y cuáles los de Pablo, después de que los fieles hubiesen orado y ayunado, recibieron una respuesta desde el cielo que decía que los huesos más grandes eran los del predicador y los más pequeños los del pescador. No obstante, se cuenta que más adelante el bienaventurado Silvestre ${ }^{38}$ los hizo pesar en una balanza distribuyéndolos en dos partes de peso equivalente y, tras consagrar las iglesias de uno y otro, colocó los huesos de los dos apóstoles en ambas.

10. En el año sexto del citado emperador Nerón el cordobés Séneca, tío paterno del poeta Lucano, preceptor de Nerón y personaje ilustre por su vida y sus conocimientos, perece por orden de Nerón tras abrirse las venas e ingerir veneno.

11. En el año del Señor 985, en las calendas de julio, durante el reinado del rey de los francos Lotario, fue asediada la ciudad de Barcelona por los paganos y fueron abatidos quinientos soldados junto con el conde Borrell en el Vallés, en el lugar que tiene por nombre Rovirans, y llevaron sus cabezas hasta Barcelona y mediante una catapulta las arrojaron en la plaza delante

36.- Entrada dedicada a Herodes Antipas (4 a. C.-39 d. C.), tetrarca de Galilea y Perea, y a Herodías, nieta de Herodes el Grande (37 a. C.-4 d. C.), que hacia el a. 28 d. C. se casó en segundas nupcias con Herodes Antipas.

37.- El papa Cornelio (251-253). Vid. Manlio Simonetti, "Cornelio, santo", Enciclopedia dei Papi, 2 vols., Roma, Instituto della Enciclopedia Italiana, 2000, vol. 1, pp. 268-272.

38.- El papa Silvestre I (314-335). Vid. Francesco ScorZa BARCELlONA, "Silvestro I, santo", Enciclopedia dei Papi, cit., vol. 1, pp. 321-333. 
de la iglesia de los santos Justo y Pastor y ese mismo día la ciudad fue conquistada ${ }^{39}$.

12. En el año del Señor 1093, en las calendas de marzo, fueron asesinados don Berenguer, arzobispo de Tarragona, Arnaldo Guillermo y Ramón de Moncada en Valencia ${ }^{40}$.

13. En el año del Señor 1099 conquistaron los cristianos de la ciudad de Jerusalén ${ }^{41}$.

14. En el añor del Señor 1101 falleció don Raimundo, conde de San Gil ${ }^{42}$. 15. En el año del Señor 1109, el día 12 de abril, se fundó la casa del Císter ${ }^{43}$.

39.- En esta noticia se mezclan dos sucesos diferentes: por un lado, la conquista y saqueo de Barcelona por Almanzor el 6 de julio de 985 (si bien, el asedio comenzó el 1 de julio, tal como indican los Cronica comunia), precedida por una batalla de difícil identificación en la que el conde Borrell II de Barcelona (947-992) fue derrotado (probablemente, en efecto, en Rovirans, cerca de Tarrasa); y por otro, la muerte del citado conde, acaecida el 30 de septiembre de 992 y sobre la que se sabe muy poco. Sobre la conquista de Barcelona, vid. Michel Zimmermann, "La prise de Barcelone par Al-Mansûr et la naissance de l'historiographe catalane", Annales de Bretagne et des pays de l'Ouest, 87 (1980), pp. 191-218 (= "La presa de Barcelona per Al-Mansur i el naixement de la historiografia catalana", en IDEM, En els orígens de Catalunya. Emancipació política i afirmació cultural, Barcelona, Edicions 62, 1989 [Llibres a l'abast, 248], pp. 71-97); Gaspar FeliU MontFort, La presa de Barcelona per Almansor: història y mitificació, Barcelona, Institut d'Estudis Catalans, 2007, pp. 18-20. Sobre el episodio final del lanzamiento de las cabezas de los defensores abatidos, vid. Manuel SÁnchez Martínez, "La expedición de Al-Mansur contra Barcelona en el 985 según las fuentes árabes", en Catalunya i França meridional a l'entorn de l'any Mil. Colloque international. C.N.R.S./ Generalitat de Catalunya. Hugues Capet 987-1987. La France de l'an Mil, Barcelona, 1991, pp. 293-301, en las pp. 299-300. Sobre Borrell II, vid. Salvador Claramunt RodríGuez, "Borrell II", DBE, vol. 9, pp. 210-212.

40.- Como he indicado más arriba, la noticia, corrupta en la versión transmitida por los Cronica comunia, hace referencia al asesinato de Berenguer de Vilademuls, arzobispo de Tarragona, víctima de Guillermo Ramón de Moncada (luego vizconde Guillermo I de Bearn) († 1224), en 1194. La crítica moderna fecha este suceso el 16 de febrero de 1194, vid. M. Coll, "Aperçu”, cit., p. 15.

41.- Reconquista de Jerusalén durante la Primera Cruzada el 15 de julio de 1099, vid. Hans Eberhard Mayer, The Crusades, Oxford, Oxford University Press, 1988², pp. 55-57; Steven Runciman, "The First Crusade: Antioch to Ascalon", A History of the Crusades, vol. 1. The First Hundred Years, ed. Marshall W. BALdwin, Madison-London, The University of Wisconsin Press, $1969^{2}$, pp. 308-341, en las pp. 336-337.

42.- Raimond de Saint-Gilles, conde de Toulouse como Raimond IV (1093-1105). Murió combatiendo en Tierra Santa en los años posteriores a la Primera Cruzada, durante el asedio de Trípoli, el 28 de febrero de 1105, vid. Harold S. FInK, "The Foundation of the Latin States, 1099-1118”, A History of the Crusades, vol. 1, cit., pp. 368-409, en la p. 396.

43.- Existe aquí, sin duda, otro error de transmisión del texto, pues en los manuscritos conservados se lee simplemente " $\mathrm{XII}^{\mathrm{o}}$ die aprilis », pero la fecha correcta sería, en latín: " XII ${ }^{\circ}$ die kalendas aprilis », el duodécimo día antes de las calendas de abril, esto es, el 21 de marzo. La referencia del año también es incorrecta, pues la abadía de Císter fue fundada por Robert de Molesmes en 1098, vid. JosephMarie CANivez, "1. Cîteaux (Abbaye)”, DHGE, vol. 12, cols. 852-874. 
16. En el año del Señor 1113, en las calendas de febrero, fue conquistada la ciudad de Mallorca ${ }^{44}$.

17. En el año del Señor 1135 murió Olegario, obispo de Barcelona y arzobispo de Tarragona ${ }^{45}$.

18. En el año del Señor 1147 fue conquistada la ciudad de Almería por el conde Ramón Berenguer el sexto día antes de las calendas de noviembre ${ }^{46}$.

19. En el año del Señor 1148, la víspera de las calendas de enero, fue conquistada la ciudad de Tortosa por el conde don Ramón Berenguer ${ }^{47}$.

20. En el año del Señor 1149, en las calendas de noviembre, fueron conquistadas la ciudad de Lérida y la villa de Fraga por el conde citado inmediatamente antes ${ }^{48}$.

21. En el año del Señor 1154, el sexto día antes de las calendas de diciembre $^{49}$, fue conquistada Siurana por el citado conde ${ }^{50}$.

22. En el año del Señor 1167, el octavo día antes de los idus de agosto ${ }^{51}$, murió Ramón Berenguer, conde de Barcelona, príncipe de Aragón y marqués de Provenza ${ }^{52}$. Este quebrantó las barreras de Hispania y conquistó las

44.- Reconquista de Palma de Mallorca por el conde Ramón Berenguer III de Barcelona (1097-1131) el 3 de abril de 1115, vid. J. F. O'Callaghan, Reconquest, pp. 35-36.

45.- Muerte de Olegario (u Oleguer), obispo de Barcelona (1116-1137) y arzobispo de Tarragona (11181137), vid. Manuel RiU Riu, “Olegario, San”, DBE, vol. 37, pp. 389-390. La fecha de los Cronica comunia es evidentemente errónea.

46.- Reconquista de Almería el 17 de octubre (no el 27 de este mes, fecha de los Cronica comunia) de 1147 por el rey de León y Castilla Alfonso VII (1126-1157) y el conde Ramón Berenguer IV de Barcelona (1131-1162), vid. J. F. O’CALlaghan, Reconquest, pp. 44-46.

47.- Reconquista de Tortosa por el conde Ramón Berenguer IV de Barcelona. La fecha exacta de la toma de la ciudad varía entre los estudiosos, para J. F. O'CALLAGHAn, Reconquest, p. 46, fue el 31 de diciembre de 1148; para Francesc Xavier Hernàndez Cardona, Història militar de Catalunya. Aproximació didàctica, vol. 2, Barcelona, Rafael Dalmau, 2004, p. 46, el 30 de diciembre de ese mismo año.

48.- Dos nuevas conquistas de Ramón Berenguer IV: Lérida y Fraga, que cayeron el mismo día, el 24 de octubre de 1149, vid. J. F. O'Callaghan, Reconquest, p. 46; F. X. Hernàndez, Història militar, vol. 2 , cit., p. 46.

49.- 26 de noviembre.

50.- Reconquista de Siurana de Prades (Tarragona) por Ramón Berenguer IV de Barcelona en 1153 , vid. Josep Maria Salrach, Història de Catalunya, vol. 2. El procés de feudalització (segles III-XII), Barcelona, Edicions 62, 1998 (reimpr., = 1987), p. 376; José Ángel SESMA MuÑoz, "IV. Aragón y Cataluña”, Historia de España Menéndez Pidal, vol. 9. La reconquista y el proceso de diferenciación política (1035-1217), coord. Miguel Ángel LADERo QuESADA, Madrid, Espasa-Calpe, 1998, pp. 661752, en la p. 680; F. X. HernàndeZ, Història militar, vol. 2, cit., p. 46. La fecha exacta de la toma de la ciudad es discutida. El asedio se inició el 29 de abril de 1153 y el 30 de noviembre de ese mismo año la ciudad ya había sido tomada. Vid. asimismo A. M. Mundó, "El concili", cit., p. XL.

51.- 6 de agosto.

52.- Muerte del conde Ramón Berenguer IV de Barcelona (1131-1162) el 6 de agosto de 1162, vid. Percy E. Schramm, "Ramon Berenguer IV", en Enric Bagué.-Joan Ferran Cabestany.-Percy E. Schramm, Els primers comtes-reis, Barcelona, Teide, 1960 (Biografies catalanes. Sèrie històrica, 4), pp. 7-51, en la p. 34. 
ciudades de Almería, Daroca, Lérida, Tortosa y Fraga y todos los territorios que están a este lado del río Ebro.

23. En el año del Señor 1180, en los idus de septiembre ${ }^{53}$, el sol sufrió un eclipe.

24. En el año del Señor 1188, el sexto día antes de las nonas de octubre ${ }^{54}$, fue conquistada la ciudad de Jerusalén ${ }^{55}$.

25. En el año del Señor 1198 santo Domingo fundó la orden de los Hermanos Predicadores en la región de Tolosa, donde predicaba con su palabra y su ejemplo contra los herejes. Éste murió y fue sepultado en Bolonia en el año decimoctavo desde el inicio de su nueva vida religiosa.

26. En el año del Señor 1206 fundó san Francisco la orden de los Hermanos Menores en las cercanías de la ciudad de Asís, junto a Santa María de la Porciuncula. Éste falleció en el año vigésimo cuarto del inicio de su vida religiosa y antes de ella tenía por nombre Juan.

27. En el año del Señor 1211 fue asesinado Pedro de Cirach, obispo de Barcelona ${ }^{56}$.

28. En el año del Señor 1212, el decimoséptimo día antes de las calendas de agosto ${ }^{57}$, se produjo un combate entre los paganos y los cristianos junto a Úbeda y ese mismo año, el duodécimo día antes de las calendas de agosto ${ }^{58}$, fue conquistada la ciudad de Úbeda ${ }^{59}$

29. En el año del Señor 1212, el undécimo día antes de las calendas de abril, fue acuñada la moneda de cuaterno por el rey don Pedro ${ }^{60}$.

53.- 13 de septiembre.

54.- 2 de octubre.

55.- Caída de Jerusalén en manos de Saladino, sultán de Egipto y Siria, el 2 de octubre de 1187, vid. Marshall W. BALDwIN, "The Decline and Fall of Jerusalem, 1174-1189", A History of the Crusades, vol. 1, cit., pp. 590-621, en las pp. 615-617; H. E. MAYer, The Crusades, cit., pp. 134-136.

56.- Pedro de Cirach (1208-1211), que murió víctima de una incursión de los sarracenos. Vid. Sebastián PUIG Y PUIG, Episcopologio de la sede barcinonense: apuntes para la historia de la Iglesia de Barcelona y de sus prelados, Barcelona, Biblioteca Balmes, 1929 (Biblioteca Histórica de la Biblioteca Balmes, Serie I, 1), pp. 179-181 y 432-437; Josep Maria Martí Bonet.-Ana Rich Abad, "Pere de Cirac", DHEC, vol. 3, p. 64.

57.- 16 de julio.

58.- 21 de julio.

59.- Batalla de Las Navas de Tolosa y reconquista de Úbeda. Las dos victorias cristianas tuvieron lugar justamente en las fechas señaladas en este cronicón, según J. F. O'CALlaGHAN, Reconquest, cit., pp. 70-74; mientras que F. X. Hernàndez, Història militar, vol. 2, cit., pp. 55-65, señala como fecha de la toma de Úbeda el 23 de julio.

60.- El 22 de marzo de 1213, siendo rey Pedro II de Aragón (1196-1213), vid. Thomas N. Bisson, "Coinages of Barcelona (1209 to 1222): The Documentary Evidence", en Studies in Numismatic Method presented to Philip Grierson, edd. Christopher N. L. Brooke.-Bernhard H. I. H. STEwart.-John G. Pollard.-Terence R. Volk, Cambridge, Cambridge University Press, 1983, pp. 193-204, en la p. 198. 
30. En el año del Señor 1221, el décimo día antes de las calendas de marzo, fue acuñada la moneda de duplo por el rey de Aragón don Jaime ${ }^{61}$.

31. En el año del Señor 1223, en las nonas de noviembre, fue capturada la ciudad de Damieta por los paganos ${ }^{62}$.

32. En el año del Señor 1225, la víspera de los idus de septiembre ${ }^{63}$, se desplazó a la isla de Ibiza junto a su ejército el señor arzobispo de Tarragona ${ }^{64}$ y ese mismo año, el quinto día antes de los idus de agosto ${ }^{65}$, conquistó el castillo de Ibiza.

33. En el año del Señor 1225, durante los meses de enero, febrero y marzo se vendió en Barcelona una cuartera de trigo por 56 sólidos y una cuartera de cebada por 40 sólidos $^{66}$.

34. En el año del Señor 1236, en los idus de septiembre ${ }^{67}$, don Jaime, ilustre rey de Aragón, en compañía de sus condes y de otros muchos nobles se dirigió desde su tierra a la isla de Mallorca con doscientas treinta y tres naves y allí tuvo lugar una batalla campal entre los cristianos y los sarracenos

61.- El 20 de febrero de 1222, en tiempos de Jaime I de Aragón (1213-1276), vid. T. N. Bisson, "Coinages", cit., p. 198.

62.- Parecen mezclarse aquí dos noticias diferentes: la reconquista de Damieta en la Quinta Cruzada el 5 de noviembre (nonas de noviembre) de 1219, y la caída de la ciudad dos años después, el 8 de septiembre de 1221, en manos del sultán de Egipto y Siria al-Kamil. Vid. Thomas C. VAn Cleve, "The Fifth Crusade", A History of the Crusades, vol. 2. The Later Crusades, 1189-1311, edd. Robert L. WolfF.-Harry R. HAZARD, Madison-Milwaukee-London, The University of Wisconsin Press, $1969^{2}$, pp. 377-428, en las pp. 397-428; H. E. MAYER, The Crusades, cit., pp. 214-227.

63.- 12 de septiembre.

64.- Reconquista de Ibiza por el arzobispo de Tarragona Guillermo de Montgrí (1234-1238) en agosto de 1235. Vid. Josep Blanch, Arxiepiscopologi de la santa església metropolitana i primada de Tarragona, vol. 1, Tarragona, 1951 (reimpr. en Tarragona, 1985 [Institut d'Estudis Tarraconenses Ramón Berenguer IV. Secció d'Arqueología i Història, 55-56]), pp. 143-148; Marià MARí, Exposició cronologico-històrica dels noms i dels fets dels arquebisbes de Tarragona, ed. Josep Maria Escolì Tuset, vol. 2, Tarragona, 1999, pp. 58-60; Anton Jordà Fernández, "Montgrí, Guillem de", DHEC, vol. 2, p. 664; Marc Sureda Jubany, "La memòria escrita d'un clergue il-lustre. Documents de Guillem de Mongrí", en Miscel-lània en honor de Josep M. Marquès, Gerona-Barcelona, Diputació de Girona, 2010, pp. 197-211; Pau Cateura Bennásser, "Montgrí, Guillermo de", DBE, vol. 35, pp. 816-817. Y además F. X. HernàndeZ, Història militar, vol. 2, cit., p. 100.

65.- 9 de agosto. P. Cateura, "Montgrí", cit., p. 816, da como fecha el 8 de agosto de 1235.

66.- Noticia recogida en Pere Benito Monclús, "Et hoc facimus propter necessitatem famis... Possibilitats de les fonts documentals catalanes per a l'estudi de les crisis alimentàries dels segles X-XIII", Acta Historica et Archaeologica Mediaevalia, 25 (2003-2004), pp. 39-62, en la n. 11 de la p. 44, donde se señala que esto sucedió en el invierno de 1226.

67.- 13 de septiembre. La fecha aceptada por la crítica moderna del inicio de la cruzada de Jaime I de Aragón contra el reino almohade de Mallorca es el 5 de septiembre de 1229, vid. J. F. O'CALLAGHAN, Reconquest, cit., pp. 89-92; F. X. HERnÀndEZ, Història militar, vol. 2, cit., pp. 90-100; José HinOJOSA Montalvo, "Jaime I", DBE, vol. 27, pp. 618-624, en la p. 621. 
y fue abatido allí Guillermo de Moncada con 23 soldados $^{68}$. Y ese mismo año, la víspera de las calendas de enero ${ }^{69}$, fue conquistada la ciudad de Mallorca por el citado rey, don Jaime.

35. En el año del Señor 1236 fue conquistada la villa de Burriana por el citado rey don Jaime $^{70}$.

36. En el año del Señor 1238, el cuarto día antes de las calendas de octubre ${ }^{71}$, fue conquistada la ciudad de Valencia por el citado rey don Jaime y el año siguiente, el tercer día antes de las nonas de julio ${ }^{72}$, el sol sufrió un eclipse en la hora sexta.

37. En el año del Señor 1266 Carlos, hermano del rey Luis de Francia y conde de Provenza, conquistó Apulia, Calabria y Sicilia y venció en batalla campal junto a Benevento al rey Manfredo de Sicilia ${ }^{73}$.

38. En el año del Señor 1268, el cuarto día antes de las nonas de agosto $^{74}$, el rey don Jaime hizo desplegar las velas para dirigirse al otro lado del mar y regresó a Aigues-Mortes el cuarto día antes de las nonas de septiembre ${ }^{75}$.

39. En el año del Señor 1268, en las calendas de diciembre, falleció el papa Clemente IV, el siervo de Dios, que con anterioridad tenía por nombre Guido Folquix, originario de la Provenza, y había estado casado y había tenido

68.- Muerte de Guillermo de Moncada, vizconde de Bearn con el título de Guillermo II (1224-1229), en septiembre de 1229, vid. P. Tucoo-Chala, Quand l'Islam, cit., pp. 242-243; Pau Cateura BennásSER, "Moncada, Guillermo de", DBE, vol. 35, p. 523.

69.- 31 de diciembre. Es la fecha correcta, vid. J. F. O'Callaghan, Reconquest, cit., p. 92.

70.- Reconquista de Burriana el 28 de julio de 1233, vid. J. F. O'CALlaghan, Reconquest, cit., p. 100. Por su parte, F. X. Hernàndez, Història militar, vol. 2, cit., p. 101, señala simplemente que la ciudad se rindió en julio de ese año.

71.- 28 de septiembre de 1238. Es la fecha correcta, vid. J. F. O'CALlaGHAN, Reconquest, cit., pp. 102-105; J. Hinojosa, "Jaime I", cit., p. 621. De nuevo es poco preciso F. X. Hernàndez, Història militar, vol. 2, cit., pp. 101-104, que se limita a decir que la ciudad fue tomada a mediados de septiembre.

72.- 5 de julio.

73.- Victoria de Carlos de Anjou sobre Manfredo de Sicilia en la batalla de Benevento el 26 de febrero de 1266, vid. Régis Rech, "Charles d'Anjou et le Limousin: la conquête du royaume de Naples chez Hélie Autenc et Géraud de Frachet”, Bibliothèque de l'École des Chartes, 158 (2000), pp. 443-473, en la p. 451. Sobre el rey Manfredo de Sicilia (1258-1266), que perdió la vida en dicho combate, vid. Pau Cateura Bennásser, "Manfredo de Sicilia", DBE, vol. 32, pp. 17-18.

74.- 2 de agosto.

75.- 2 de septiembre. La fallida expedición de Jaime I de Aragón con destino a Tierra Santa para tomar parte en las Cruzadas se produjo en el verano del año 1269, vid. Ferrán Soldevila, Vida de Jaume I el Conqueridor, Barcelona, Base, $1969^{2}$ (Biblioteca biográfica catalana, 14), pp. 277-281, según este estudioso el rey habría partido de Barcelona el 6 de septiembre y habría regresado a AiguesMortes el 16 de ese mismo mes debido al mal tiempo del mar; José Luis Villacañas, Jaume I el Conquistador, Madrid, Espasa, 2003, pp. 658-668, quien da como fechas del viaje: salida el 4 de septiembre, regreso el 11 de ese mismo mes; y J. HinoJosA, "Jaime I", cit., p. 622, que indica también el 4 de septiembre como fecha de la salida de la flota catalano-aragonesa de Barcelona y no precisa la fecha del regreso. 
descendencia, y que después fue arzobispo de Narbona, más tarde cardinal de Sabina y finalmente fue llamado a desempeñar el puesto de sumo pontífice y permaneció en el pontificado durante tres años, nueve meses y veintiún días ${ }^{76}$.

40. En el año del Señor 1270, el sexto día antes de las nonas de julio ${ }^{77}$, Luis, rey de los francos por la gracia de Dios, hizo desplegar las velas en Aigues-Mortes para atacar a los sarracenos y se dirigió a Túnez con sus hijos y las esposas de sus hijos y el noveno día antes de las calendas de agosto ${ }^{78}$ conquistó Cartago y allí murió en paz.

76.- El papa Clemente IV (5.II.1265-29.XI.1268), cuyo nombre era Guy Foucois, vid. Norman KAMP, "Clemente IV", Enciclopedia dei Papi, cit., vol. 2, pp. 401-411.

77.- 2 de julio. Todas las dataciones de esta entrada son correctas. Sobre el episodio aquí relatado, vid. Jim Bradbury, The Capetians, Kings of France 987-1328, London-New York, Hambledon Continuum, 2007, pp. 234-236.

78.- 24 de julio. 